\title{
Exploratory Analysis of Time from HIV Diagnosis to ART Start, Factors and effect on survival: A longitudinal follow up study at seven teaching hospitals in Ethiopia
}

\author{
Alula M. Teklu ${ }^{1 *}$, Kesetebirhan Delele ${ }^{2}$, Mulu Abraha ${ }^{3}$, Bekele Belayhun ${ }^{4}$, \\ Esayas Kebede Gudina ${ }^{5}$, Abiy Nega ${ }^{1}$
}

\footnotetext{
OPEN ACCESS

Citation: Alula M. Teklu, Kesetebirhan Delele, Mulu Abraha, et al. Exploratory Analysis of Time from HIV Diagnosis to ART Start, Factors and effect on survival: A longitudinal follow up study at seven teaching hospitals in Ethiopia. Ethiop $\mathrm{J}$ Health Sci 2017;27(si1):17-28. doi: http://dx.doi.org/10.4314/ejhs.v27i1.3S.

Received: February 1, 2016

Accepted: August 12, 2016

Published: March 15, 2017

Copyright: (C) 2017 Alula MT et al. This

is an open access article distributed under

the terms of the Creative Commons

Attribution License, which permits

unrestricted use, distribution, and reproduction in any medium, provided the original author and source are credited.

Funding:Center for Disease Control and

Prevention (CDC)

Competing Interests: The authors declare

that this manuscript was approved by all

authors in its form and that no competing interest exists.

Affilation and Correspondence:

${ }^{1}$ MERQ Consultancy Services, Addis

Ababa, Ethiopia

${ }^{2}$ University of South Africa, Addis

Ababa, Ethiopia

${ }^{3}$ JHU-TSEHAI, Addis Ababa, Ethiopia

${ }^{4}$ Ethiopian Public Health Association

${ }^{5}$ Department of Internal Medicine,

Jimma University, Jimma, Ethiopia

*Alula M Teklu. E-mail:

ateklu72@gmail.com
}

\begin{abstract}
Background: the HIV care in Ethiopia has reached 79\% coverage. The timeliness of the care provided at the different levels in the course of the disease starting from knowing HIV positive status to ART initiation is not well known. This study intends to explore the timing of the care seeking, the care provision and associated factors.

Methods: This is a longitudinal follow-up study at seven university hospitals. Patients enrolled in HIV care from September 2005 to December 2013 and aged $\geq 14$ years were studied. Different times in the cascade of HIV care were examined including the duration from date HIV diagnosed to enrollment in HIV care, duration from enrollment to eligibility for ART and time from eligibility to initiation of ART. Ordinal logistic regression was used to investigate their determinants while the effect of these periods on survival of patients was determined using cox-proportional hazards regression.

Results: 4159 clients were studied. Time to enrollment after HIV test decreased from 39 days in 2005 to 1 day after 2008. It took longer if baseline CD4 was higher, and eligibility for ART was assessed late. Young adults, lower baseline CD4, HIV diagnosis $<2008$, late enrollment, and early eligibility assessment were associated with early ART initiation. Male gender, advanced disease stage and lower baseline CD4 were consistent risk factors for mortality.

Conclusion and recommendation: Time to enrollment and duration of ART eligibility assessment as well as ART initiation time after eligibility is improving. Further study is required to identify why mortality is slightly increasing after 2010.
\end{abstract}

Key words: HIV, HIV testing, enrollment, eligibility, antiretroviral therapy, mortality, Ethiopia. 
INTRODUCTION

Ethiopia is one of the countries which were hard hit by HIV. The prevalence was $6.4 \%$ in 2001 and 4.4 in $2003(1,2)$. The current prevalence of $1.2 \%$ leaves the country with close to 741,478 people living with HIV (3). There are 439,301 people who have ever been started on ART. In terms of total numbers the country has reached ART coverage of $79 \%$ (4).

Several factors contributed positively towards this rapid expansion of the services. The unprecedented level of financial support received through PEPFAR and Global Fund, availability of guidelines for public-health approach, and strong commitment from the Ministry of Health/Federal HIV/AIDS Prevention and Control Office together with local leadership and partners contributed to these remarkable achievements (4).

The focus of many reports has been on the number starting treatment and retention. One of the major aims of the national anti-retroviral program is to ensure that HIV-positive individuals are diagnosed, rapidly linked to an organized program of chronic HIV care, and placed on antiretroviral therapy as soon as they become eligible (5). It has been proved that if HIV infection is detected early and prompt linkage and treatment initiated, mortality and health care expenditure declines. Late initial access to ART poses serious risks. For instance, in South Africa, delaying initiation of ART as briefly as 30 days was found to pose a high risk of death (6). In numerous studies, earlier access to ART - as measured by CD4 cell count - after a patient's CD4 cell count falls to near 200 , has been shown to be related to a lower risk of mortality (7).

Linkage to care can be problematic. While the design and organization of the care cascade varies greatly depending on the country, access to ART in most low- and middle-income countries is generally a multi-step process, in which there is substantial loss at each step. In studies in subSaharan Africa, a median of $41 \%$ of patients were found to be lost prior to receiving CD4 staging results, a median of $54 \%$ of those receiving CD 4 counts are lost prior to being found eligible for ART, and a median of $32 \%$ of those found eligible for ART are lost prior to starting ART (8). Under the Ethiopian national ART program, in 2005-2008, $61 \%$ of persons testing HIV-positive were reported to have been "immediately" linked to chronic HIV care (9). A detailed analysis of 2,191 adult patients who were enrolled in chronic HIV care between January 2003 and December 2008, more than half the patients were linked from HIV testing to chronic care within one day, and half of those placed on chronic care initiated ART within 16 days. Waiting times were longest for patients entering care prior to the start of the national program, and shortest for patients entering during in the period 2005 to 2006 (10). There are various risk factors for delayed enrollment in HIV care. Some of these include lack of awareness, mental illness, fear of stigma and stigma (11). Other factors were responsible for late ART initiation in a multilevel study in Cameroon including male gender, knowledge about the disease, presence of integrated PMTCT service, place of residence, being single, level of education and period of treatment $(12,13)$. Most studies define late presentation as having low baseline CD4 cell count or other clinical criteria like being in advanced WHO Stage at presentation However, additional data is lacking on the typical time course for linkage to care and placement on ART in Ethiopia irrespective of baseline clinical characteristics.

This study aims to use the advanced clinical monitoring (ACM) cohorts to provide an exploratory analysis of the time course from HIV diagnosis, to enrollment in chronic care, to ART start. It also intends to look at the effect of the duration of each stage on survival of the patients.

\section{METHODS}

Study setting and design: This study uses the Advanced Clinical Monitoring (ACM) cohort from the seven university hospitals providing chronic HIV care. The full description of the study design, participant selection, data collection process and full description of the study cohort can be found in the methodology paper (14). In short, this was a prospective observational longitudinal study. Study subjects were enrolled randomly from those in HIV care in the selected health facilities.

Study sample and period: All adults and adolescents more than 14 years of age and

DOI: http://dx.doi.org/10.4314/ejhs.v27i1.3S 
enrolled in the study cohort were included in the current study. This includes clients enrolled in care between 2005 and 2013.

Independent variables: Age, gender, baseline WHO stage, baseline CD4 cell count, disclosure status, and period of enrolment in to HIV care are the explanatory variables.

\section{The Operational definitions used}

- HIV test is a laboratory test based on sample of blood to identify the presence of Human Immunodeficiency Virus in the body of a person. Test kit used is based on the national algorithm used at the time of testing (15).

- Enrollment into HIV care is the process of being register in a health facility providing chronic HIV care services for the purpose of receiving antiretroviral therapy (ART) services. This is provided in clinics specially availed for this purpose (16).

- Eligibility for ART is determined by looking at a set of predefined criteria according to the treatment guideline at a given time. The cutoff for eligibility of treatment with antiretroviral therapy (ART) has varied over time (16-18). The baseline CD4 cell count cut-off has risen from $\leq 200$ (before 2008), 201 to 350 for WHO Stage III patients (2008$2010), \leq 350$ (2011-2014) and at the time of analysis, it was at $\leq 500$. As for clinical ART initiation criteria it has shifted from starting only WHO stage IV clients to WHO stage 3 patients at time of analysis.

- ART initiation is the process of administering highly active antiretroviral therapy (HAART) to a patient eligible for treatment with ART. Adherence preparation is provided for a defined time according to patient needs (16).

- Survival in HIV care is defined as being alive at time of last observation. For clients that were lost to follow-up, tracing was done by phone, or home visit. For this purpose adherence supporters were available at each clinic who routinely received data from data clerks keeping records of clients with missed appointment. Adherence supporters would trace clients accordingly and update records. Clients found to be taking medications at a different facility were censored as were those lost to follow-up cases during survival analysis (14).

Main study and outcome variables: Time from HIV diagnosis to enrollment in chronic HIV care (T-1), time from enrollment in chronic HIV care to eligibility for starting ART (T-2) and time from eligibility for ART to treatment initiation (T-3) were the main study variables. Each time variable was used to study its effect on the next time variable and survival that is effect of T-1 on $\mathrm{T}-2$, T-3, and survival; effect of T-2 on T-3, and survival; and effect of T-3 on survival as shown on fig 1 .
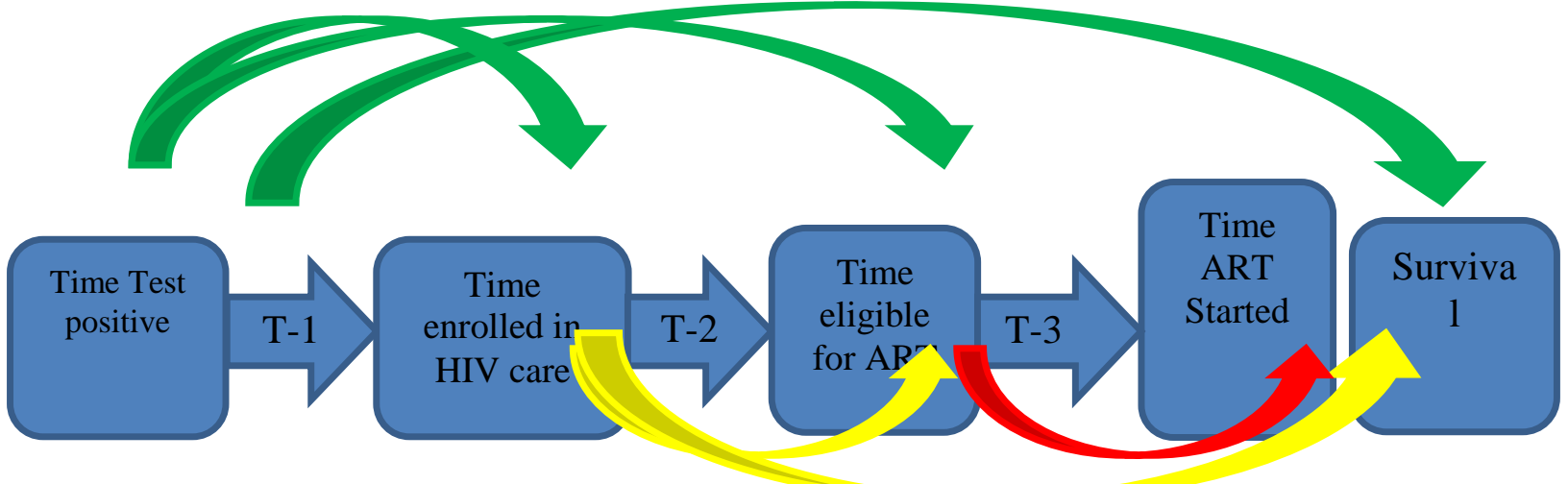

Figure 1: Different time periods in the cascade of ART provision from time HIV status is known to enrollment (T1), to eligibility (T-2), to ART initiation (T-3), and finally to survival.

Data source: De-identified and de-linked electronic record was used as data source. The data set was maintained at each study site. Data clerks were trained and assigned for the sole purpose of maintaining this database. All entered data was regularly checked for

DOI: http://dx.doi.org/10.4314/ejhs.v27i1.3S 
consistency and accuracy with the original paper based medical records. This was done by onsite external support through a central data manager as well as at country level. Regular telephone co nference was held to ensure compliance to data recording and database updating procedures.

Analysis: Stata statistical software Version 12 was used to do statistical analysis. There were missing data elements from the following variables: age (12\%), and gender (2\%). Multiple imputations (multivariate normal regression) was used to estimate the missing values which was then used for analysis. All other variables were used for predicting missing values. As for descriptive statistics, number and percentages are used to provide description for categorical variables while median is used for continuous variables like time. Association between variables was determined with ordinal logistic regression whenever outcome variable was ordinal in nature (T-1, T-2, and T-3). Effect of independent variables on survival was determined by Cox-proportional hazards regression analysis. Only those variables significant during bi-variable analysis were included in the final model. Clients who were lost to follow-up or transferred to another facility or stopped treatment were censored from follow-up. Lost to follow-up was defined as not appearing for appointment for more than one month. Clients that were lost to follow-up were identified and traced by adherence supporters as described earlier. The effect of the changing eligibility criteria was accounted for by the use of time period categorization (2005-2007, 2008-2010, and 2011-2013), which is similar to the changing eligibility criteria, in regression analysis for modeling determinants for $\mathrm{T}-1$ and $\mathrm{T}-3$. For modeling time to eligibility (T-2) and survival, the changing eligibility criteria was examined by taking this time period and reviewing outputs separately for each time period (2005-2007, 2008-2010, and 2011-2013) since comparing one group to another is not possible because of slower progression to eligibility and possibility for higher survival as the CD4 cut-off increased. Site level variability was accounted for during cox-regression analysis by stratification using site ID (19). Alph-value was set at 0.05 .

\section{RESULTS}

All 4,159 patients eligible for study that that fell in the period free ART was initiated (after 2004) who were older than 14 years were in the adult and adolescent cohort were included. Baseline characteristics of the patients are displayed in Table -1 below. Most patients (92\%) were above 24 years of age. More than half $(61 \%)$ were female and $32 \%$ of all patients fall in the category of baseline CD4 count which is less than $100.83 \%$ of patients have disclosed their HIV status.

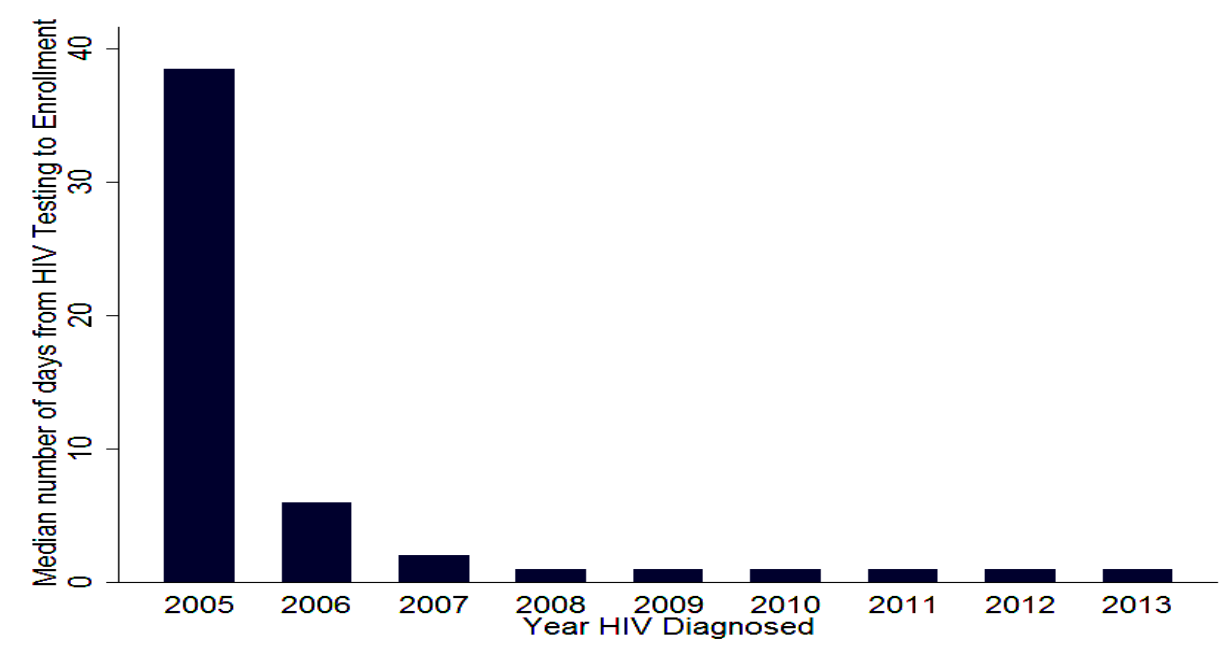

Figure 2: Trend of duration of time from knowing HIV status to enrollment in chronic HIV care, T-1 
Table 1: Baseline characteristics of study subjects

\begin{tabular}{lll}
\hline Variable & Category & Number (\%) \\
\hline Age & $15-24$ & $312(7.48 \%)$ \\
& $>24$ & $3855(92.51 \%)$ \\
Sex & Female & $2532(60.76 \%)$ \\
Baseline WHO Stage & Male & $1635(39.23 \%)$ \\
Baseline CD4 cell count & I or II & $1394(33.45 \%)$ \\
& III or IV & $2773(66.54 \%)$ \\
Disclosure & $<100$ & $1313(31.50 \%)$ \\
Period HIV diagnosed & $100-349$ & $2485(59.63 \%)$ \\
& $>349$ & $369(8.85 \%)$ \\
Time from HIV test to enrollment & No & $700(16.79 \%)$ \\
& Yes & $3467(83.20 \%)$ \\
& $2005-2007$ & $1853(44.46 \%)$ \\
Time from Enrollment to eligibility & $2008-2010$ & $1678(40.26 \%)$ \\
& $2011-2013$ & $636(15.26 \%)$ \\
& $\leq 1$ week & $3112(74.68 \%)$ \\
Time from Eligibility to ART initiation & 1 week-1 month & $677(16.24 \%)$ \\
& $>1$ month & $378(9.07 \%)$ \\
& $\leq 1$ week & $2316(55.57 \%)$ \\
& 1 week-1 month & $571(13.70 \%)$ \\
& $>1$ month & $1280(30.71 \%)$ \\
& $\leq 1$ week & $858(20.59 \%)$ \\
Last Status & 1 week-1 month & $734(17.61 \%)$ \\
& 1 month- 1 year & $955(22.91 \%)$ \\
& $>1$ year & $587(14.08 \%)$ \\
& Active & $1033(24.79 \%)$ \\
& Dead & $3247(77.92 \%)$ \\
& Lost & $464(11.13 \%)$ \\
& Transferred to other facility & $120(2.87 \%)$ \\
& Other & $223(5.71 \%)$ \\
& & \\
& &
\end{tabular}

Time form HIV test to Enrollment: In 2005, the median duration of T-1 was 39 days and progressively dropped to one starting 2008 as shown in figure 2. Overall, around $75 \%$ of clients were enrolled in the first week after knowing their HIV status (Table 1). Upon examining factors which affect the length of T-1 (Table 2), it can be seen that among those who eventually started ART, early enrollment was more likely in the earlier years of chronic HIV care (before 2007). Relatively speaking, it took longer for those with higher baseline CD4 cell count (>349) to enroll in care.

Time form Enrollment to Eligibility: As seen on figure 3 below, the median duration for T-2 has a declining trend after 2008 and remains at or below 2 days after that. Around $64 \%$ of clients are found to be eligible within one week of enrollment (Table 1).

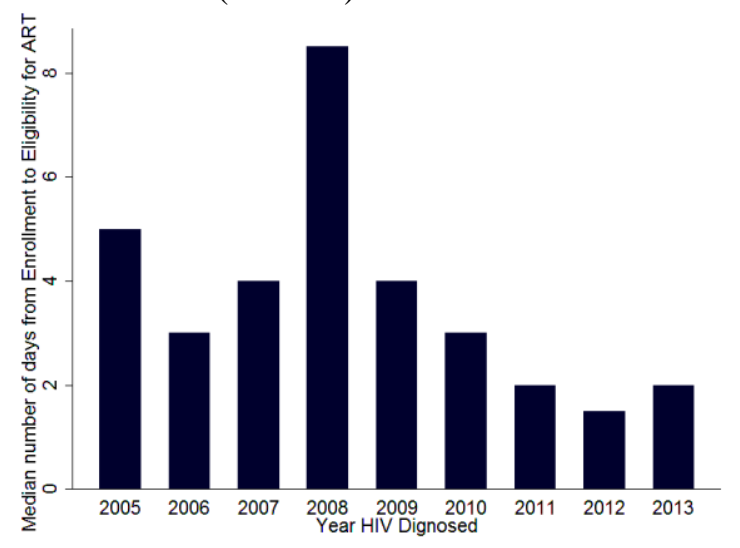

Figure 3: Trends of time from enrollment to eligibility - T-2 
Table 2: Determinants of time from knowing HIV status to enrollment in chronic HIV care in ACM sites, 2005- 2013.

\begin{tabular}{|c|c|c|c|c|c|c|c|}
\hline \multirow[t]{2}{*}{ Variable } & \multirow[t]{2}{*}{ Category } & \multicolumn{3}{|c|}{ Unadjusted } & \multicolumn{3}{|c|}{ Adjusted } \\
\hline & & OR & $\mathbf{P}>\mathbf{Z}$ & $95 \% \mathrm{CI}$ & OR & $\mathbf{P}>\mathbf{Z}$ & $95 \% \mathrm{CI}$ \\
\hline \multirow[t]{2}{*}{ Age } & $15-24$ & 1 & & & & & \\
\hline & $>24$ & 1.17 & 0.26 & $0.89-1.54$ & & & \\
\hline \multirow[t]{2}{*}{ Sex } & Female & 1 & & & 1 & & \\
\hline & Male & 1.07 & 0.15 & $0.93-1.24$ & 1.12 & 0.11 & $0.97-1.30$ \\
\hline \multirow[t]{2}{*}{ Stage } & I or II & 1 & & & & & \\
\hline & III or IV & 1.12 & 0.13 & $0.97-1.30$ & 0.94 & 0.42 & $0.80-1.10$ \\
\hline \multirow[t]{3}{*}{ CD4 } & $<100$ & 1 & & & 1 & & \\
\hline & $100-349$ & 1.17 & 0.05 & $1.00-1.36$ & 1.15 & 0.10 & $0.98-1.35$ \\
\hline & $>349$ & 1.87 & 0.00 & $1.46-2.39$ & 1.77 & $\mathbf{0 . 0 0}$ & $1.37-2.27$ \\
\hline \multirow[t]{2}{*}{ Disclosure } & No & 1 & & & & & \\
\hline & Yes & 1.08 & 0.40 & $0.90-1.31$ & & & \\
\hline \multirow[t]{3}{*}{ Period HIV diagnosed } & 2005-2007 & 1 & & & 1 & & \\
\hline & $2008-2010$ & 0.44 & 0.00 & $0.38-0.51$ & 0.44 & 0.00 & $0.38-0.52$ \\
\hline & 2011-2013 & 0.32 & 0.00 & $0.25-0.41$ & 0.31 & 0.00 & $0.25-0.40$ \\
\hline
\end{tabular}

Table 3: Determinants of time to eligibility after enrollment into chronic HIV care in ACM sites, 20052013.

\begin{tabular}{|c|c|c|c|c|c|c|c|c|}
\hline \multirow[t]{3}{*}{ Variable } & \multirow[t]{3}{*}{ Category } & \multicolumn{7}{|c|}{ Period HIV diagnosed } \\
\hline & & \multicolumn{2}{|c|}{ 2005-2007 } & \multicolumn{2}{|c|}{ 2008-2010 } & \multicolumn{3}{|c|}{ 2011-2013 } \\
\hline & & $\begin{array}{l}\text { Adj. } \\
\text { OR }\end{array}$ & $\mathbf{P}>\mathbf{z}$ & $\begin{array}{l}\text { Adj. } \\
\text { OR }\end{array}$ & $\mathbf{P}>\mathbf{z}$ & Adj. & Odds Ratio & $\mathbf{P}>\mathbf{z}$ \\
\hline \multirow[t]{2}{*}{ Age } & $15-24$ & 1 & & 1 & & & 1 & \\
\hline & $>24$ & 1.30 & 0.14 & 0.85 & 0.41 & & 0.77 & 0.48 \\
\hline \multirow[t]{2}{*}{ Sex } & Female & 1 & & 1 & & & 1 & \\
\hline & Male & 0.83 & 0.06 & 0.70 & 0.00 & & 0.88 & 0.50 \\
\hline \multirow[t]{2}{*}{ Stage } & I or II & 1 & & 1 & & & 1 & \\
\hline & III or IV & 0.47 & $\mathbf{0 . 0 0}$ & 0.61 & 0.00 & & 0.80 & 0.23 \\
\hline \multirow{3}{*}{ CD4 } & $<100$ & 1 & & 1 & & & 1 & \\
\hline & $100-349$ & 1.89 & 0.00 & 2.62 & 0.00 & & 1.58 & 0.02 \\
\hline & $>349$ & 2.84 & 0.00 & 3.25 & 0.00 & & 1.68 & 0.11 \\
\hline \multirow[t]{2}{*}{ Disclosure } & No & 1 & & 1 & & & 1 & \\
\hline & Yes & 0.79 & 0.07 & 0.74 & 0.02 & & 1.29 & 0.26 \\
\hline \multirow[t]{3}{*}{ Time from test to enrolment } & $\leq 1$ week & 1 & & 1 & & & 1 & \\
\hline & 1 week-1 month & 1.47 & $\mathbf{0 . 0 0}$ & 1.69 & 0.00 & & 1.83 & 0.02 \\
\hline & $>1$ month & 1.44 & 0.01 & 3.52 & 0.00 & & 0.70 & 0.55 \\
\hline
\end{tabular}

As seen on Table 3 below, it can be seen that relatively speaking, asymptomatic patients and those with lower baseline CD4 cell count) were assessed to be eligible early on. It took longer time for those with higher CD4 cell count at baseline to become eligible and this was true across all time periods. In the period 2008-2010, late eligibility assessment was additionally associated with non-disclosure and female gender.

Time from Eligibility to ART initiation: As seen on Figure 4 below, T-3 has been increasing over the years. $48 \%$ of client started treatment within one month of eligibility for ART (Table 1). Upon examining the factors it took longer for younger adults, asymptomatic patients, those

DOI: http://dx.doi.org/10.4314/ejhs.v27i1.3S 
with higher CD4 $(\geq 100)$, those diagnosed with HIV after 2007, those who were enrolled within one week of HIV diagnosis and those who became eligible 1 month after enrollment to initiate ART after eligibility (Table 4).

Table 4: Factors affecting time ART started among those who were eligibility for treatment in ACM sites, 2005-2013.

\begin{tabular}{|c|c|c|c|c|c|c|c|}
\hline \multirow[t]{2}{*}{ Variable } & \multirow[t]{2}{*}{ Category } & \multicolumn{3}{|c|}{ Unadjusted } & \multicolumn{3}{|c|}{ Adjusted } \\
\hline & & OR & $\mathbf{P}>\mathbf{Z}$ & $95 \% \mathrm{CI}$ & OR & $\mathbf{P}>\mathbf{Z}$ & $95 \% \mathrm{CI}$ \\
\hline \multirow[t]{2}{*}{ Age } & $15-24$ & 1 & & & 1 & & \\
\hline & $>24$ & 0.75 & 0.01 & 0.61-.91 & 0.77 & 0.01 & 0.63-0.95 \\
\hline \multirow[t]{2}{*}{ Sex } & Female & 1 & & & & & \\
\hline & Male & 1.03 & 0.57 & $0.92-.15$ & & & \\
\hline \multirow[t]{2}{*}{ Stage } & I or II & 1 & & & 1 & & \\
\hline & III or IV & 0.67 & 0.00 & $0.60-.76$ & 0.92 & 0.16 & $0.81-1.04$ \\
\hline \multirow[t]{3}{*}{ CD4 } & $<100$ & 1 & & & 1 & & \\
\hline & $100-349$ & 1.40 & 0.00 & $1.24-.58$ & 1.15 & 0.02 & $1.02-1.31$ \\
\hline & $>349$ & 1.43 & 0.00 & $1.15-.77$ & 1.12 & 0.28 & $0.90-1.41$ \\
\hline \multirow{2}{*}{ Disclosure } & No & 1 & & & 1 & & \\
\hline & Yes & 0.87 & 0.06 & $0.75-.00$ & 0.90 & 1.83 & 0.78-1.05 \\
\hline \multirow[t]{3}{*}{ Period HIV diagnosed } & 2005-2007 & 1 & & & 1 & & \\
\hline & $2008-2010$ & 1.23 & 0.00 & 1.09-.39 & 1.36 & 0.00 & $1.20-1.55$ \\
\hline & $2011-2013$ & 1.70 & 0.00 & $1.45-.99$ & 1.92 & 0.00 & $1.62-2.26$ \\
\hline \multirow[t]{3}{*}{ Time from test to enrolment } & $\leq 1$ week & 1 & & & 1 & & \\
\hline & 1week-1 month & 0.77 & 0.00 & $0.65-.90$ & 0.80 & 0.01 & $0.68-0.94$ \\
\hline & $>1$ month & 1.03 & 0.78 & $0.85-.24$ & 0.79 & 0.03 & 0.65-0.97 \\
\hline \multirow[t]{3}{*}{ Time from enrolment to eligibility } & $\leq 1$ week & 1 & & & 1 & & \\
\hline & 1week-1 month & 0.81 & 0.00 & $0.68-.95$ & 0.80 & 0.01 & $0.68-0.95$ \\
\hline & $>1$ month & 8.06 & 0.00 & 6.83-.51 & 8.48 & 0.00 & 7.15-10.07 \\
\hline
\end{tabular}

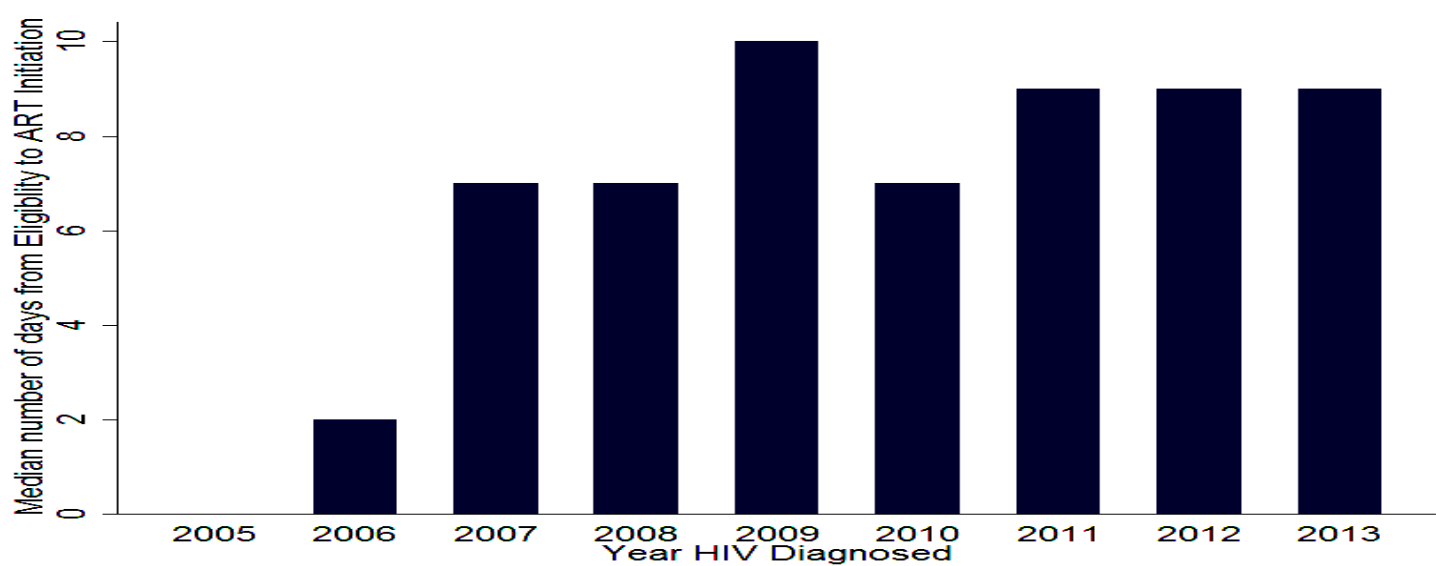

Figure 4: Trends in time from eligibility for ART to initiation of treatment-T-3

Treatment outcome: The majority $(78 \%)$ of clients was still active in care at the end of follow-up while $11 \%$ died and $3 \%$ were lost to follow-up (Table 1).
Mortality: As can be seen in Table 5 below, male gender, advanced disease stage and very low baseline CD4 cell counts $(<100)$ were risk factors for mortality across the different 
treatment periods. Even though direct comparison is not possible among the different time periods, mortality was found to be higher among those diagnosed with HIV after 2010.
Early enrollment, eligibility assessment (mostly), and initiation of treatment later after eligibility were found not to be risk factor for mortality. Neither did age, and disclosure status.

Table 5: Factors affecting survival among those that started ART in ACM sites, 2005-2013.

\begin{tabular}{|c|c|c|c|c|c|c|c|c|}
\hline \multirow[t]{3}{*}{ Variable } & \multirow[t]{3}{*}{ Category } & \multicolumn{7}{|c|}{ Period enrolled in HIV care } \\
\hline & & \multicolumn{2}{|c|}{$2005-2007$} & \multicolumn{2}{|c|}{ 2008-2010 } & \multicolumn{3}{|c|}{ 2011-2013 } \\
\hline & & $\begin{array}{l}\text { Adj. } \\
\text { Haz. } \\
\text { Ratio }\end{array}$ & $\mathbf{P}>\mathbf{Z}$ & $\begin{array}{l}\text { Adj. } \\
\text { Haz. } \\
\text { Ratio }\end{array}$ & $\mathbf{P}>\mathbf{Z}$ & Adj. & Haz. Ratio & $\mathbf{P}>\mathbf{z}$ \\
\hline \multirow[t]{2}{*}{ Sex } & Female & 1 & & 1 & & & 1 & \\
\hline & Male & 1.53 & 0.01 & 1.61 & 0.00 & & 1.10 & 0.70 \\
\hline \multirow[t]{2}{*}{ Stage } & I or II & 1 & & 1 & & & 1 & \\
\hline & III or IV & 2.07 & $\mathbf{0 . 0 0}$ & 1.81 & 0.00 & & 2.06 & 0.01 \\
\hline \multirow[t]{3}{*}{ CD4 } & $<100$ & 1 & & 1 & & & 1 & \\
\hline & $100-349$ & 0.39 & $\mathbf{0 . 0 0}$ & 0.46 & 0.00 & & 0.52 & 0.02 \\
\hline & $>349$ & 0.57 & 0.01 & 0.32 & 0.01 & & 0.68 & 0.40 \\
\hline \multirow[t]{4}{*}{ Time from Eligibility to ART initiation } & 0 days & 1 & & 1 & & & 1 & \\
\hline & $\leq 1$ week & 0.90 & 0.60 & 0.85 & 0.53 & & 0.85 & 0.67 \\
\hline & 1 week-1 month & 0.68 & 0.08 & 0.79 & 0.33 & & 0.49 & 0.07 \\
\hline & $>1$ month & 0.92 & 0.67 & 0.74 & 0.24 & & 0.44 & 0.04 \\
\hline
\end{tabular}

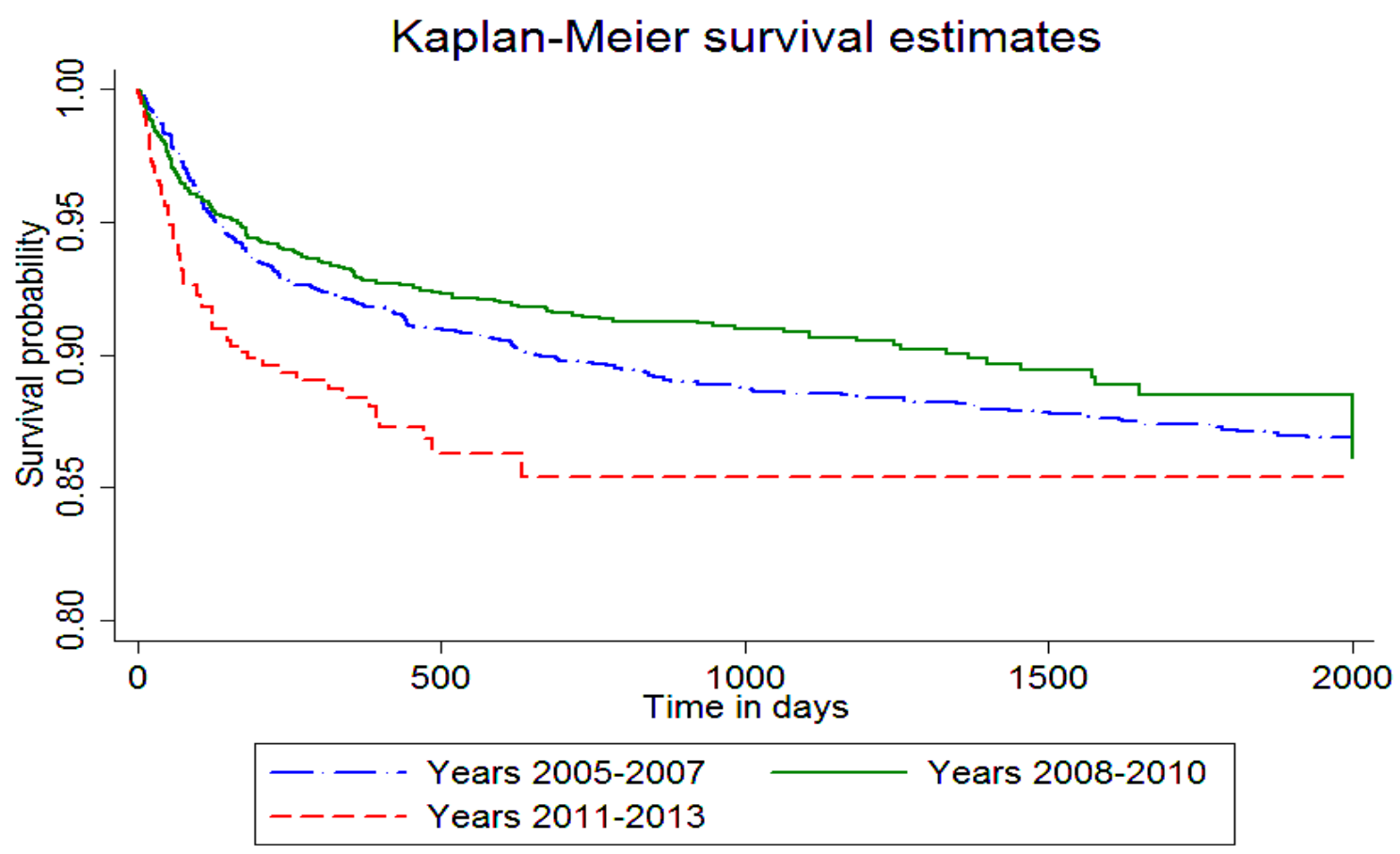

Figure 5: Kaplan Meier Survival Estimates on Time to Death by HIV Diagnosis Year

DOI: http://dx.doi.org/10.4314/ejhs.v27i1.3S 


\section{DISCUSSION}

All in all, the different milestones in the continuum of HIV care provision were being met in relatively better time intervals. Time to enrollment (T-1), and time to eligibility (T-2) were within one week for nearly $75 \%$ and $64 \%$ of clients, while ART initiation was within one month following eligibility in $48 \%$ of cases. The percentage of clients active in care was $77 \%$ in the study cohort, while those who died amounted to $11 \%$.

The pattern of late enrollment of clients earlier in the roll out of the national free antiretroviral treatment program (2005-2007) could be attributed to service delivery factors like weak referral and linkage at the time where the program was still in its infancy. This has greatly improved later on as peer supporters or educators started providing linkage and counseling support. In Ethiopia this was started in 2007. (20-23) Another factor potentially attributable for this may be the technical assistance provided by international non-governmental university partners through PEPFAR (US President's Emergency Plan for AIDS Relief) program. (24) Late enrollment could also be due to patient factors as evidenced by longer time for linkage after diagnosis among those with higher CD4 cell count $(25,26)$. This may be because healthier patients didn't feel the need for immediate follow-up as it happens with many chronic illnesses (27). On the other hand, earlier enrollment for those with lower CD4 cell count may point to a very acceptable health seeking behavior since these are the clients who needed care sooner than later. However, this must be seen separately form the more common case where those with lower CD4 or advanced WHO stage fail to link to care at all for several reasons including accessibility of health facilities. (28)

The fact that the majority of clients become eligible in the first week of enrollment indicates that first, the assessment to determine eligibility was being carried out effectively in most of the study facilities; second, most clients enrolling in care becoming eligible indicates the late appearance of most clients for treatment after progressing to advanced disease stages. (29-31) The fact that more healthy patients (asymptomatic and those with higher baseline CD4 cell count) became eligible as time went by may be a reflection of the fact that eligibility criteria changed from lower $(<200)$ to higher $(<350)$ CD4 cut-off. (32) It is no surprise that clients with higher baseline $\mathrm{CD} 4$ cell count took longer time to become eligible which is in line with slow CD4 progression for those who present to care soon after infection or with higher CD4 cell count. (18, 33)

A significant proportion of clients started ART soon after eligibility (48\%); that is, within one week. This is rather a worrisome pattern since it is important to take time to prepare clients for treatment well before commencing ART. National as well as international guideline clearly state that at least 2 to 3 visits be taken for adherence counseling and preparation and start other important preventive therapies like cotrimoxazol preventive therapy. $(5,18,34)$ The potential negative effect to this may be reflected in poor treatment adherence, increased risk for side effects or even mortality especially whenever there are hidden opportunistic infections like tuberculosis. (35-37) Increased risk for mortality has also been documented in this study among those starting ART sooner as compared to those starting ART after one week from eligibility experiencing much better survival. This was statistically significant after 2011 with better long term survival for those starting ART one month after eligibility. Therefore, from this point of view, it is good news that the median ART initiation time is progressively increasing and approaching the two weeks limit as shown in figure 4 . However, long term mortality was modeled to be better if early ART was not associated with lost to follow-up or mortality in a study done in sub-Saharan Africa. (38) In the current study, late initiation after eligibility was associated with younger age, diagnosis after 2007 and late eligibility assessment (>1 month) and higher baseline CD4 count. Accessibility is not an issue in this scenario since most of the clients were residents near study sites or within the town the health facility in question. It may be the result of late CD4 cell count assessment or at times negligence by providers to implement improved eligibility criteria. That may be the reason behind most of these cases being 
recorded in the period where these adjustments tool place.

Other important factors associated with mortality include being male gender, having low baseline CD4, and advanced disease stage at ART initiation. These factors were reported in several studies as well that consistently show that late presentation is associated with adverse outcomes. (39)

This study shades light in the progress the HIV care in the study sites took from the earlier periods to the very recent past. It also identifies key challenges that may require further investigation as the program evolves. For instance, with the current cut off for eligibility being at an ever higher level of 500 CD4 cell counts, people may become even more reluctant to start treatment because of the general wellbeing they experience or late enrollment. (4) This may hamper efforts to initiate other interventions like positive living, tuberculosis prophylaxis, and so on. Therefore, as further criteria are introduced that promote initiation of treatment for more healthier people, the role of peer educators or adherence supporters and health care providers may become even more important to stress the advantage of starting treatment sooner than later. Another curious finding is that while disclosure of HIV status was high at $83 \%$ as reported in other studies as well, it was not associated with timely enrollment, ART initiation, or better survival even though it is known that clients who have disclosed have better adherence to medication. $(40,41)$ At the same time, the study has identified lingering implementation challenges resulting in late enrollment, late eligibility assessment and late ART initiation which require further follow-u. Finally, further study is required as to why mortality is higher among those diagnosed with HIV after 2011 which is paradoxical since eligibility has progressively increased and patients are starting care earlier.

\section{Limitations}

The primary limitation of this study is that it includes only those patients who reached the point of ART treatment. Therefore, it is subject to survival bias. $(19,42)$ The distribution of time courses from diagnosis to treatment may not be representative of the overall $\mathrm{HIV}+$ population for a number of reasons. The ACM cohort has a bias toward identifying those patients with better access to care, earlier. It does not include HIV+ patients who were diagnosed but never access clinical care or those who died or were lost to follow up before they started ART having started follow-up.

The other limitation is data quality. There were missing data elements for which statistically estimation was done through imputation. Even though this represents probably the best scientific guess, some outcomes may still have been affected. Another issue is the level of lost to follow-up. At 3\%, even though, it is much lower than previous reports from other studies $(10,43)$, it still possess a challenge to make definitive conclusion concerning mortality estimates and determinants.

\section{REFERENCES}

1. Federal Ministry of Health. AIDS in Ethiopia 5th ed. 2004.

2. Federal Ministry of Health. AIDS in Ethiopia 6th ed. 2005.

3. Ethiopian Public Health Institute. HIV Related Estimates and Projections for Ethiopia-2015. 2015.

4. Federal HIV/AIDS Prevention and Control Office. Country progress report on the HIV response, 2014. 2014.

5. World Health Organisation. Consolidated guidelines on the use of antiretroviral drugs for treating and preventing HIV infection: recommendations for a public health approach. Geneva, Switzerland2013.

6. Lawn SD, Myer L, Harling G, Orrell C, Bekker L-G, Wood R. Determinants of mortality and nondeath losses from an antiretroviral treatment service in South Africa: implications for program evaluation. Clinical Infectious Diseases. 2006;43(6):7706.

7. ART - LINC Collaboration of the International Databases to Evaluate AIDS. Antiretroviral therapy in resource-limited settings 1996 to 2006: patient characteristics, treatment regimens and monitoring in subSaharan Africa, Asia and Latin America. Tropical medicine \& international health: TM \& IH. 2008;13(7):870.

8. Rosen S, Fox MP. Retention in HIV care between testing and treatment in sub-Saharan

DOI: http://dx.doi.org/10.4314/ejhs.v27i1.3S 
Africa: a systematic review. PLoS medicine. 2011;8(7):e1001056.

9. Assefa Y, Damme WV, Mariam DH, Kloos H. Toward universal access to HIV counseling and testing and antiretroviral treatment in Ethiopia: looking beyond HIV testing and ART initiation. AIDS patient care and STDs. 2010;24(8):521-5.

10. Mulissa Z, Jerene D, Lindtjørn B. Patients present earlier and survival has improved, but pre-ART attrition is high in a six-year HIV cohort data from Ethiopia. PloS one. 2010;5(10):e13268.

11. Bhowmik A, Rewari B, Guha SDR, Bhandari S, Roy S. Factors responsible for delayed enrollment for anti-retroviral treatment. Journal of Nepal Health Research Council. 2013.

12. Ndawinz JD, Chaix B, Koulla-Shiro S, Delaporte E, Okouda B, Abanda A, et al. Factors associated with late antiretroviral therapy initiation in Cameroon: a representative multilevel analysis. Journal of Antimicrobial Chemotherapy. 2013:dkt011.

13. Lahuerta M, Lima J, Nuwagaba-Biribonwoha H, Okamura M, Alvim MF, Fernandes R, et al. Factors associated with late antiretroviral therapy initiation among adults in Mozambique. PloS one. 2012;7(5):e37125.

14. Teklu AM. Advanced Clinical Monitoring of ART in Ethiopia: Establishing a multicenter longitudinal clinical cohort study. Ethiopian Journal of Health Sciences. 2016(in print).

15. The Federal Democratic Republic of Ethiopia Ministry of Health. Provider-Initiated HIV Testing And Counselling. 2010.

16. Ministry of Health. Chronic HIV Care with Antiretroviral Therapy and Prevention: Guideline for first line health workers. 2007.

17. World Health Organisation. Antiretroviral therapy for HIV infection in adults and adolescents: recommendations for a public health approach-2010 revision. 2010.

18. Ministry of Health. National comprehensive HIV care and treatment training for health care providers, participant manual, Ethiopia. 2014.

19. Collet D. Modelling survival data in medical research. 2nd ed. London: Chapman \& Hall.; 2003.
20. Kranzer K, Govindasamy D, Ford N, Johnston $\mathrm{V}$, Lawn SD. Quantifying and addressing losses along the continuum of care for people living with HIV infection in sub-Saharan Africa: a systematic review. Journal of the International AIDS Society. 2012;15(2).

21. Alagaw A, Godana W, Taha M, Dejene T. Factors associated with Antiretroviral Treatment Adherence among Adult Patients in WolaitaSoddo Hospital, Wolaita Zone, Southern Ethiopia. Sci J Public Health. 2014;2:69-77.

22. Gardner LI, Metsch LR, Anderson-Mahoney P, Loughlin AM, Del Rio C, Strathdee S, et al. Efficacy of a brief case management intervention to link recently diagnosed HIVinfected persons to care. Aids. 2005;19(4):423-31.

23. ITECH Ethiopia. A Pragmatic Approach to Maximizing Adherence to Long-Term Treatment And Retention in Chronic Illness Care. 2014.

24. El-Sadr WM, Holmes CB, Mugyenyi P, Thirumurthy H, Ellerbrock T, Ferris R, et al. Scale-up of HIV treatment through PEPFAR: a historic public health achievement. Journal of acquired immune deficiency syndromes (1999). 2012;60(Suppl 3):S96.

25. Hoffman S, Wu Y, Lahuerta M, Kulkarni SG, Nuwagaba-Biribonwoha H, Sadr WE, et al. Advanced disease at enrollment in HIV care in four sub-Saharan African countries: change from 2006 to 2011 and multilevel predictors in 2011. AIDS (London, England). 2014;28(16):2429-38.

26. Khoury Z, Silva RS, Villela W. Factors Associated with a Delay in Seeking HIV/AIDS Treatment in São Paulo, Brazil. AIDS and Behavior. 2015;19(4):679-83.

27. Alvarez-Uria G. Factors associated with delayed entry into HIV medical care after HIV diagnosis in a resource-limited setting: data from a cohort study in India. PeerJ. 2013;1:e90.

28. De Lima YV, Evans D, Page-Shipp L, Barnard A, Sanne I, Menezes CN, et al. Linkage to care and treatment for TB and HIV among people newly diagnosed with $\mathrm{TB}$ or HIV-associated TB at a large, inner city South African hospital. PloS one. 2013;8(1). 
29. Federal HIV/AIDS Prevention and Control Office \& Federal Ministry of Health. Guideline for Antiretroviral Therapy, Ethiopia. 2008.

30. Gelaw YA, Senbete GH, Adane AA, Alene KA. Determinants of late presentation to HIV/AIDS care in Southern Tigray Zone, Northern Ethiopia: an institution based casecontrol study. AIDS research and therapy. 2015;12(1):1.

31. Abaynew Y, Deribew A, Deribe K. Factors associated with late presentation to HIV/AIDS care in South Wollo ZoneEthiopia: a casecontrol study. AIDS research and therapy. 2011;8(1): 1 .

32. Federal Ministry of Health. Technical updates on adopted recommendations on adolescent and adult anti-retroviral treatment. Addis Ababa, Ethiopia. 2013.

33. Chaiyasin N, Sungkanuparph S. Rate of CD4 Decline and Factors Associated with Rapid CD4 Decline in Asymptomatic HIV-Infected Patients. Journal of the International Association of Providers of AIDS Care (JIAPAC). 2016;15(1):3-6.

34. Department of Health and Human Services [USA]. Guidelines for the use of antiretroviral agents in HIV-1 infected adults and adolescents. New York: Department of Health and Human Services 2013.

35. Wondwosen Amogne GA, Abiy Habtewold, Getnet Yimer, Eyasu Makonnen, Alemayhu Worku, Anders Sonnerborg, Eleni Aklillu, Lars Lindquist. Efficacy and Safety of Antiretroviral Therapy Initiated One Week after Tuberculosis Therapy in Patients with CD4 Counts < 200 Cells/ $\mu \mathrm{L}:$ TB-HAART Study, a Randomized Clinical Trial. PLoS ONE 10(5):e0122587 doi:101371/journalpone0122587. 2015.
36. Federal Ministry of Health. Guideline for clinical and Programatic management of TB, TB/HIV and Leprosy in Ethiopia. FIFTH ed. Addis Ababa, Ethiopia2013.

37. World Health Organisation. Guideline for Intensified TB case-findings and isoniazid Preventive Therapy for HIV positive patients in resource constrained settings. Geneva, Switzerland.2011.

38. Anglaret X, Scott CA, Walensky RP, Ouattara E, Losina E, Moh R, et al. Could early antiretroviral therapy entail more risks than benefits in sub-Saharan African HIV-infected adults? A model-based analysis. Antiviral therapy. 2013;18(1):45.

39. Sobrino-Vegas P, Moreno S, Rubio R, Viciana $\mathrm{P}$, Bernardino JI, Blanco JR, et al. Impact of late presentation of HIV infection on short-, mid-and long-term mortality and causes of death in a multicenter national cohort: 2004 2013. Journal of Infection. 2016.

40. Rotzinger A, Locatelli I, Reymermier M, Amico S, Bugnon $\mathrm{O}$, Cavassini $\mathrm{M}$, et al. Association of disclosure of HIV status with medication adherence. Patient Education and Counseling. 2016.

41. Gadisa T, Tymejczyk O, Kulkarni SG, Hoffman S, Lahuerta M, Remien RH, et al. Disclosure History Among Persons Initiating Antiretroviral Treatment at Six HIV Clinics in Oromia, Ethiopia, 2012-2013. AIDS and behavior. 2016:1-12.

42. Polit DF, Beck CT. Nursing Research: Principles and Methods: Lippincott Williams \& Wilkins; 2004.

43. Yirdaw KD, Jerene D, Gashu Z, Edginton M, Kumar AM, Letamo Y, et al. Beneficial Effect of Isoniazid Preventive Therapy and Antiretroviral Therapy on the Incidence of Tuberculosis in People Living with HIV in Ethiopia. PloS one. 2014;9(8):e104557. 